\title{
Value co - creation through crowdsourcing: The case of Squadhelp competition platform
}

\author{
Elena Galateanu $(\text { Avram })^{1 *}$ and Silvia Avasilcai ${ }^{1}$ \\ 1"Gheorghe Asachi” Technical University of Iasi, Department of Engineering and Management, Blvd D. Mangeron 29, 700050, Iasi, \\ Romania
}

\begin{abstract}
The increasing attention for open innovation processes within organizational development context is materialized through new product and/or services development. The main approach into this direction is to enhance the crowdsourcing features within internal innovation processes, especially value co-creation. The emerging industries, such as creative ones, are using this approach in order to innovate and to enhance collaborative power of creative co-producers. By shifting the co-creation from customers only to multiple stakeholders' engagement there can be observed the actors' evolution within the innovation ecosystems. Thus, in this paper there will be assessed the key features of crowdsourcing processes in terms of the most relevant transitions in value co-creation theory. The use of case study approach will reveal relevant insights from the Squadhelp competition platform in terms of innovation, crowdsourcing activities and creative co-producers.
\end{abstract}

\section{Introduction}

Innovative products/ services development requires the use of different approaches from the companies' point of view. By participating within a specific business ecosystem, the economic entities acknowledged the major relevance of collaboration enhancement and the use of open innovation and crowds as the engines for boosting the creative potential and innovation processes.

As the concept of business ecosystem evolved into the innovative one, there can be traced various innovation techniques which were used by the leaders within different industries. However, there still remains the necessity to understand how companies co-create value with their partners, especially in case of innovation ecosystems. The most relevant stakeholders within an innovation ecosystem are often seen as resource providers [1]. Within this context the crowds are taken for granted, as an integrative part of innovation ecosystem [1]. From this point of view, this paper aims to present the most relevant key features of innovation processes, to underline the major importance of open innovation within an innovation ecosystem, to identify the specific crowdsourcing activities within an emergent creative ecosystem and to provide an illustrative example by using the case study approach on the Squadhelp competition platform.

\section{Innovation ecosystems and the creative potential of the emergent industries}

Innovation ecosystems emerged as result from business ecosystems to more specific type of ecosystems, whose main concern is innovation [1]. According to Adner an innovation ecosystem has a customer-centric structure [2], where all involved actors are working collectively in order to create and deliver appropriate value [3]. Such value can be emphasized through the enhancement of creative potential and technology development as it was stated by E. Galateanu (Avram) and S. Avasilcai [4]. Adner and Kapoor emphasized the major importance of technological challenges that needs to be overcome in order for end users to benefit from its development and implementation [5]. Oh, Philips, Park and Lee suggested that the use of innovation ecosystem can be supported by several reasons, such as:

- Different value created by different actors,

- The performance of this system depends on continuous development

- Establishing relationships between actors and emergence of innovative strategies through continuous and voluntary involvement of human resource [6].

The emergent industries can be perceived as a potential source of creativity, the most relevant feature lying in innovation creation. From this point of view Lazzeretti stated that the creative potential can be achieved by a group of individuals by quantifying their feelings and perceptions which bestow on the creative processes a leadership position [4], [7]. By following this statement there can be traced an important transition from customer co-creation to multiple stakeholders' involvement into value creation process in order to unlock the creative potential.

\subsection{Co - creation transitions: The key features and motivations}

\footnotetext{
* Corresponding author: egalateanu@tuiasi.ro
} 
Pera, Occhiocupo and Clarke explored the importance of value co-creation transitions within business ecosystems context. The authors identified two main development trends [8]:

- From consumers to multiple stakeholders' involvement

- From various stakeholders to ecosystems stakeholders.

According to their findings, the relations between various stakeholders can be considered as the main trigger for value creation, especially value co-creation.

The first transition emphasizes the shift from consumer to multiple stakeholders' engagement into value creation process, presented in table 1 .

Table 1. The first transition: from consumers to multiple stakeholders

\begin{tabular}{|c|c|}
\hline Key Aspects & Description \\
\hline Prerequisites & $\begin{array}{l}\text { - Potential and existing consumers as } \\
\text { the main target }\end{array}$ \\
\hline $\begin{array}{l}\text { Engaging } \\
\text { Actors }\end{array}$ & - Consumers and suppliers \\
\hline Process & $\begin{array}{l}\text { - Knowledge sharing } \\
\text { - Collaborative actions } \\
\text { - Direct links between actors }\end{array}$ \\
\hline Results & $\begin{array}{l}\text { - Problem formulation } \\
\text { - Negotiation } \\
\text { - Resources allocation }\end{array}$ \\
\hline Roles & $\begin{array}{l}\text { - Co-designers, co-creators, co- } \\
\text { producers, co-implementors }\end{array}$ \\
\hline Landscape & $\begin{array}{l}\text { - Through entire network of business } \\
\text { networks }\end{array}$ \\
\hline
\end{tabular}

This approach is more likely to characterize the transition from supply chain to value chain, where consumers represent the source of innovation [9].

The second transition implies an ecosystem's point of view. The engagement of multiple stakeholders into value creation process underlines their contributions within a business ecosystem context. From this point of view the key aspects are adaptation and flexibility of the actors [8], presented in table 2 .

Table 2. The second transition: from multiple stakeholders to business ecosystem [8]

\begin{tabular}{|l|l|}
\hline \multicolumn{1}{|c|}{ Key Aspects } & \multicolumn{1}{|c|}{ Description } \\
\hline Prerequisites & - Stakeholders relationships \\
\hline Engaging & $\begin{array}{l}\text { - A system of stakeholders from } \\
\text { Actors }\end{array}$ \\
\hline Process & $\begin{array}{l}\text { - Adaptation and evolution } \\
\text { - Value exchange } \\
\text { - Direct links between actors from } \\
\text { different networks }\end{array}$ \\
\hline Results & $\begin{array}{l}\text { - The success of the business } \\
\text { ecosystem } \\
\text { - Resources integration }\end{array}$ \\
\hline Roles & - Co-creators of value \\
\hline Landscape & - Through entire business ecosystem \\
\hline
\end{tabular}

From this point of view the value creation process became more complex and is described by the engagement of actors from various business networks. According to
Merz, Zarantonello and Grappi the perceived value can be created only by common effort of multiple actors [10]. Customers play an important role within a co-creation process as they are a potential source of design, requirements and customized new products [11].

However, stakeholders' engagement into value cocreation is relevant in terms of expected benefits and Perra, Occhiocupo and Clarke identified a few motives for stakeholders' engagement as follows:

- Exploiting the creative potential of relevant customers

- The use of resources from other stakeholders

- "the constellation of services, goods and design" [8, pp 4035].

Finnerty, Kucherbaev, Tranquillini and Convertino stated that the quality of crowdsourcing tasks or projects relies on the workers motivation [12]. From this point of view the authors introduced a reward - based schema and identified a few types of rewards, as presented in table 3.

Table 3. The second transition: from multiple stakeholders to business ecosystem [12]

\begin{tabular}{|l|l|}
\hline \multicolumn{1}{|c|}{ Reward Type } & \multicolumn{1}{|c|}{ Description } \\
\hline No reward & $\begin{array}{l}\text { - Without extra reward for project's } \\
\text { completion }\end{array}$ \\
\hline Courteousness & $\begin{array}{l}\text { - Use the word "please" } \\
\text { - Asking the participants to finish the } \\
\text { tasks in terms of time and accuracy }\end{array}$ \\
\hline Fixed & $\begin{array}{l}\text { - Gaining benefits despite their poor } \\
\text { performance, if it the case }\end{array}$ \\
\hline Dynamic & $\begin{array}{l}\text { - Different rewards } \\
\text { - Calculated based on participants } \\
\text { performance } \\
\text { - Quicker tasks completion means a } \\
\text { higher reward }\end{array}$ \\
\hline
\end{tabular}

\subsection{The use of crowdsourcing in value co - creation process}

The use crowdsourcing mechanisms provides valuable insights into the value co-creation process and the exploitation of creative potential. Dai, Wang, Jin and Ma suggested that crowdsourcing is especially important in terms of performed tasks [13]. The authors stated that there should be identified three main components for crowdsourcing activities: specific tasks, participants and the platform, which facilitates and links the participants to the tasks [13].

Alexa and Avasilcai identified two types of participants in crowdsourcing activities [14]:

- Seekers - those who propose the tasks as specially designed projects

- Solvers - those who provide the creative potential, it can be anybody with no restriction.

The most relevant aspect, as it was pointed by Dai, Wang, Jin and $\mathrm{Ma}$ [13], is the decision-making process. Accordingly, Zhang, Shangguan and Yuan linked this strategy to the crowdsourcing platform and stated that the decision-making process is time limited and it should provide fast results to the specific tasks [15]. From this point of view in crowdsourcing is preferred the approach 
where individual capabilities are matching the specific provided tasks [16].

Crowdsourcing can be seen also as an innovative type of recruitment of potential creative workforce. According to Behrend, Sharek, Meade and Wiebe the crowdsourcing comprises three main features [17]:

- The remuneration of the solvers

- Online recruitment, not restricted by geographical criteria

- The solvers are recruited only for specific tasks. From this point of view crowdsourcing is narrowing the attention to the target groups [18] and is presenting interesting insights in comparison to open innovation, as follows in table 4.

Table 4 The main differences between open innovation and crowdsourcing [18].

\begin{tabular}{|c|c|c|}
\hline Key Aspects & $\begin{array}{c}\text { Open } \\
\text { Innovation }\end{array}$ & Crowdsourcing \\
\hline Main Target & $\begin{array}{l}\text { - Customers' } \\
\text { integration } \\
\text { - Innovation } \\
\text { process within } \\
\text { the companies }\end{array}$ & $\begin{array}{lr}\text { - Different } & \text { target } \\
\text { groups } & \\
\text { - A } & \text { broader } \\
\text { coverage } & \text { of } \\
\text { processes } & \\
\end{array}$ \\
\hline $\begin{array}{l}\text { Strategy } \\
\text { Actors }\end{array}$ & $\begin{array}{l}\text { - Interaction } \\
\text { with different } \\
\text { types of } \\
\text { stakeholders }\end{array}$ & $\begin{array}{l}\text { - Interaction } \\
\text { between the } \\
\text { company and the } \\
\text { crowd }\end{array}$ \\
\hline Type of call & $\begin{array}{l}\text { - Predefined by a } \\
\text { contract }\end{array}$ & $\begin{array}{l}\text { - Open call launched } \\
\text { to the crowd }\end{array}$ \\
\hline Openness & $\begin{array}{l}\text { - Open type } \\
\text { - Defines the } \\
\text { base for } \\
\text { product } \\
\text { development }\end{array}$ & $\begin{array}{l}\text { - Closed type } \\
\text { - Intellectual } \\
\text { property rights }\end{array}$ \\
\hline Purpose & $\begin{array}{l}\text { - Collective } \\
\text { improvement } \\
\text { of the product } \\
\text { - Granting } \\
\text { access to } \\
\text { specific } \\
\text { elements of the } \\
\text { product }\end{array}$ & $\begin{array}{l}\text { - Creating items } \\
\text { individually and / } \\
\text { or collaboratively }\end{array}$ \\
\hline
\end{tabular}

\section{Value co - creation within the Squadhelp community}

Squadhelp represents a community of freelancers, namely experts, whose main concern is to innovate and provide a full service and support for brands construction for companies, start-ups, and other actors [19]. The main objective of this community is to provide innovation of traditional agency business model [19]. Established in 2011, Squadhelp nowadays numbers a community of over 70 thousand creatives who contribute to creation, validation and growing new brands [19].

According to their vision there are several aspects which differentiate the community, such as:

- Provides agency experience without specific price tag - through naming contest the clients benefit from support of branding consultants without the implication of special agencies.

- Branding support - through specially designed services Squadhelp allows their clients to benefit from targeting their potential customers, test their choices, avoid legal risks and secure their trademark

- Ensures the highest quality - ensures quality of generated ideas through specially designed algorithm, which provides a ranking for potential creatives

\subsection{Squadhelp provided services}

As it was stated before the Squadhelp competition platform offers the most quality and comprehensive package of related and support services. The wide range of specially designed services represents an essential difference between competition platforms and competition marketplaces. From this point of view the community includes services as it is shown in table 5, which are related to co - ideation of names or logos, validation of the submitted ideas, online verification of ideas availability, legal advising services, validation of the chosen name and legal support service for trademark or name registration [20] - [26].

\subsection{Co - creation within Squadhelp community}

The current theories emphasize the relevance of cocreators within a value co-creation process. From this point of view there should be identified the most important actors who participate in the co-designing process within the Squadhelp community.

According to their vision in the value co-creation process there are involved:

- A community of designers - especially for logo designing and naming services

- A community of branding consultants - are relevant for branding services, as well as for platinum customers

- Legal advisors - provide legal assessment of trademarks, assistance in trademark registration process

- Customers - Squadhelp addresses their services to a wide range of actors: companies, small enterprises, start-ups who are engaging into branding activities or are new in the market.

Each of these actors are involved differently into the value co-creation process according to the provided service.

\subsubsection{Value co - creation process within the Squadhelp community}

According to the crowdsourcing theory value co creation can embrace the form of competition/contest. From this point of view the Squadhelp defines the cocreation process through several essential stages [27]:

- Start the competition - represents the stage

Table 5 Squadhelp provided services [20] - [26] 


\begin{tabular}{|c|c|}
\hline Targeting services & Specific actions \\
\hline Naming & $\begin{array}{l}\text { - Contest activities } \\
\text { - Interactive observation of active contests } \\
\text { - Defining filters criteria } \\
\text { - Addresses to different industries }\end{array}$ \\
\hline Logo design & $\begin{array}{l}\text { - Creation of logo through contests } \\
\text { - Offers a logo template } \\
\text { - Limited timeline of the contest (not exceed } 7 \text { days) } \\
\text { - Interactive feedback }\end{array}$ \\
\hline Taglines & $\begin{array}{l}\text { - Maximum } 5 \text { days contest timeline } \\
\text { - Engage creative potential of the community } \\
\text { - Offers tagline template } \\
\text { - Checking the trademark for any conflicts }\end{array}$ \\
\hline Business names for sale & $\begin{array}{l}\text { - Complementary trademark evaluation action } \\
\text { - Data base of name for sale } \\
\text { - Narrowing filters by: category, style, length, keywords } \\
\text { - Fixed and low pricing package } \\
\text { - Offers names for business and brands, and names for premium domain }\end{array}$ \\
\hline Audience testing & $\begin{array}{l}\text { - Identifies the targeted clients } \\
\text { - Fast and reliable feedback from the targeted audience } \\
\text { - Resonates the chosen name with clients' perception } \\
\text { - Use specific instruments for data collection } \\
\text { - Provides an extensive demographic research } \\
\text { - Duration of the research up to } 3 \text { days }\end{array}$ \\
\hline Trademark research \& filing & $\begin{array}{l}\text { - Legal assessment of the trademark and chosen name } \\
\text { - The use of online or mobile channels of communication } \\
\text { - Provides support services for trademark registration (U. S. Patent and } \\
\text { Trademark Office USPTO) and efficient use }\end{array}$ \\
\hline Managed agency services & $\begin{array}{l}\text { - Platinum type of competitions } \\
\text { - Provides the advising services throughout the entire project } \\
\text { - Assistance in contest } \backslash \text { s requirements or project } \\
\text { - Granting unlimited access to the client } \\
\text { - Support and legal services applied }\end{array}$ \\
\hline
\end{tabular}

where the customer provides a brief description of the future project. For this stage Squadhelp implemented a specially designed template which comprises the information about basic requirements and which will be distributed to the community

- Ideas generation - at this stage the customer will receive dozens of ideas according to the specified requirements. At the same time those ideas (names or logos) will be verified online for their availability

- "collaborate and communicate" - describe the interactive communication between the customer and the designers. At this stage the customer or project holder should provide.

feedback for designers, comment the ideas privately, rank the submissions

- Validation stage - at this stage the customer benefit from assessment process of the chosen name, domain, legal risk, trademark, linguistic evaluation and target groups testing

- Choose the winner - this stage provides information about the winning idea. The customer should choose the best idea and start the registration process of the name.

\subsubsection{Contest content}

Each started contest comprises basic information such as the brief of the contest, to whom it is addressing, provided reward and the type of reward (guaranteed reward) [28]. Along with the contest briefing there can be traced a short description of the contest holder and the contest timeline.

Also, there can be found statistics of submitted, withdrawn and active ideas and number of rated entries. As the co-creation process is an interactive one and the customer should provide feedback all along the entire submission process, there can be find the statistics of customers" feedback. From this point of view the contest holder should respond with qualificatives as: "Love it", "Like it", "On right track" and "No, thank you".

\subsubsection{Contest pricing packages}

At this point each potential contest holder or seeker have the opportunity to choose the pricing package for the future contest. From this point of view Squadhelp provides four different packages [29]:

- Bronze - provided services do not exceed specified budget. According to this package the contest holder benefit from a low budget pricing, at least 100 ideas submitted and online matching availability of the name and domain

- Gold - includes up to 300 expected submissions, along with verification of domain 
availability the seeker will benefit also from assistance for trademark assessment, strict privacy terms and promotion on Squadhelp homepage

- Platinum - according to this package the contest holder should expect around 400 submitted ideas. It also includes audience assessment and testing of chosen names, a legal trademark assessment and validation. This package includes almost all services provided by Squadhelp which are also: linguistic assessment, refund options and the use of collaborative tools;

- Managed - this exclusive package promotes one-on-one coaching with branding experts. Basically, this approach is preferred for the seekers who chose to acquire an agency experience.

Based on the provided pricing packages the customers can chose the services they want to benefit from the competition platform.

\subsubsection{Additional crowdsourcing instruments and resources}

Although the Squadhelp provides an interactive contests platform, additionally it also comprises a few instruments and resources which are relevant for potential or already existing customers. From this point of view in order to choose a name the seeker can chose from names database and receive a suggestion from the marketplace.

Also, there can be found the information for contest holders and for participants. In first case the Squadhelp provides tips for contest holders in terms of ranking choices, how to provide fast and reliable feedback, information regarding domain registration and how to reward the contestants based on the quality of their work [30]. In this case the Squadhelp provides a unique pointing system which can be seen as a quality filter. The contestants there are provided with a few guidelines such as [31]:

- Read and research if the submission idea respects seeker's requirements

- Do not submit low quality ideas

- Comment and ask if there is the case

- Use the provided resources to come up with a new name

- Use the activity feed frequently in order to provide high quality ideas and to adjust the entries.

Along with these general guidelines there can be found also a discussion forum where there can be traced all relevant and frequently asked questions [32] and a blog which comprises all tips and novelties in terms of naming, branding and logo creation for creatives [33].

\section{Conclusions}

Innovation ecosystems are relevant in the current research as they provide valuable insights in terms of innovation diffusion across and within an organisation. Nowadays, innovation became an essential key feature which describes the most relevant internal or external processes. From this point of view value co-creation represents a development process which promotes innovation. However, there should be pointed that the shift from a single customer to multiple stakeholders' involvement into co-creation process had a major impact on organisational activity. The use of crowdsourcing within value co-creation emphasised the birth of new types of customers naming seekers (contest holders) and solvers (contestants or participants). Based on contest type of value co-creation there can be enhanced the creative potential of young designers or branding experts as it is illustrated by the Squadhelp competition platform. The key feature which differentiate it from a crowdsourcing marketplace is the wide range of provided services. The Squadhelp provides integrative, all in one, branding services starting from choosing the business or brand's name until research, assessment and its validation. Additionally, they offer legal risk assessment and assistance in trademark registration at Trademark Office. Different pricing packages influences contest holders' benefits.

This work was supported by a grant of the Romanian National Authority for Scientific Research and Innovation, CNCS/CCCDI - UEFISCDI, project number PN-III-P2-2.1PED-2016-0689, within PNCDI III

\section{References}

1. L. Scaringella, A. Radziwon, Innovation, entrepreneurial, knowledge, and business ecosystems: Old wine in new bottles? Technological Forecasting \& Social Change (2017) retrieved from: /10.1016/j.techfore.2017.09.023, to be published

2. R. Adner, Match your innovation strategy to your innovation ecosystem, Harvard Business Review, 84 (4), pp 98 - 107, (2006)

3. B. Walrave, M. Talmar, K. Podoynitsyna, G. Romme, G. Verbong, A multi - level perspective on innovation ecosystems for path - breaking innovation, Technological Forecasting and Social Change, (2017) retrieved from: 10.1016/j.techfore.2017.04.011, to be published

4. E. Galateanu (Avram) and S. Avasilcai, Emerging creative ecosystems: platform development process, Annals of the Oradea University, Fascicle of Management and Technological Engineering, XXVI (XVI), 3, pp 5 - 10 (2017)

5. R. Adner and R. Kapoor, Innovation ecosystems and the pace of substitution: Re - examining technology $\mathrm{S}$ - curves, Strategic Management Journal, 37 (4), pp $625-648,(2016)$

6. D. S. Oh, F. Phillips, S. Park and E. Lee, Innovation ecosystems: A critical analysis, Technovation 54, pp $1-6,(2016)$

7. L. Lazzeretti, "Cultural and Creative Industries" in Creative Industries and Innovation in Europe: Concepts, Measures and Comparative Case Studies, 
L. Lazzeretti, Ed. Routledge, London and New York, pp. $1-20$ (2013)

8. R. Perra, N. Occhiocupo, J. Clarke, Motives and resources for value co - creation in a multi stakeholder ecosystem: A managerial perspective, Journal of Business Research 69 (10), pp 4033 4041 (2016)

9. E. Galateanu (Avram), S. Avasilcai, Value co creation process in business ecosystem, Annals of the Oradea University, Fascicle of Management and Technological Engineering XXIII (XIII), 3, pp 169 - 174 (2014)

10. M. Merz, L. Zarantonello, S. Grappi, how valuable are your customers in the brand value co - creation process? The development of a customer co creation value (CCCV) scale, Journal of Business Research 82, pp 79 - 89 (2018)

11. E. Galateanu (Avram), S. Avasilcai, Symbiosis process in business ecosystem, Advanced Materials Research 1036, pp 1066 - 1071 (2014)

12. A. Finnerty, P. Kucherbaev, S. Tranquillini, G. Convertino, Keep it simple: Reward and task design in crowdsourcing, Proceedings of

13. W. Dai, Y. Wang, Q. Jin, J. Ma, An integrated incentive framework for mobile crowdsourced sensing, Tsinghua Science and Technology 21 (2), pp 146 - 156, (2016)

14. L. Alexa, S. Avasilcai, A. Bujor, An open innovation marketplace: The case of Innocentive, Annals of the Oradea University, Fascicle of Management and Technological Engineering, XXVI (XVI), 3, pp 1 4 (2017)

15. X. Zhang, L. Shangguan, Y. Yuan, A crowd wisdom management framework for crowdsourcing systems, IEEE Access 4, pp 9764 - 9774, (2016)

16. M. Z. Tunio, H. Luo, W. Cong, A. R. Gilal, A. Abro, $\mathrm{S}$. Wenhua, Impact of personality on task selection in crowdsourcing software development: A sorting approach, IEEE Access 5, pp 18287 - 18294, (2017)

17. T. Behrend, D. Sharek, A. Meade, E. Wiebe, The viability of crowdsourcing for survey research, Behaviour Research Methods 43, pp 800 - 813 (2011)

18. Y. Zhao, Q. Zhu, Evaluation on crowdsourcing research: Current status and future direction, Information System Frontiers 16, pp 417 - 434 (2014)

19. Squadhelp, about us, retrieved from: https://www.squadhelp.com/AboutUs, accessed at: 19.04.2018 (2018)

20. Squadhelp, naming service, retrieved from: https://www.squadhelp.com/branding-marketingnaming-contests\#contest type filter $=1$, accessed at 19.04.2018 (2018)

21. Squadhelp, Logo design, retrieved from: https://www.squadhelp.com/LogoDesignContests, accessed at: 19.04.2018 (2018)
22. Squadhelp, taglines, retrieved from: https://www.squadhelp.com/AdvertisingSlogansTag lines, accessed at 20.04.2018 (2018)

23. Squadhelp, names for sale, retrieved from: https://www.squadhelp.com/premium-domains-forsale $? \mathrm{q}=\& \mathrm{hPP}=10 \& \mathrm{idx}=$ Marketplace $\& \mathrm{p}=0$, accessed at 20.04.2018 (2018)

24. Squadhelp, audience testing, retrieved from: https://www.squadhelp.com/brand-name-testing, accessed at: 20.04.2018 (2018)

25. Squadhelp, trademark research \& filing, retrieved from: http://helpdesk.squadhelp.com/squadhelpservices/trademark-filing-package, accessed at 21.04.2018 (2018)

26. Squadhelp, managed contest service, retrieved from: http://helpdesk.squadhelp.com/squadhelpservices/squadhelp-managed-contest-service, accessed at 21.04.2018 (2018)

27. Squadhelp, how it works? retrieved from: https://www.squadhelp.com/how-it-works, accessed at 22.04.2018 (2018)

28. Squadhelp, contest content, retrieved from: https://www.squadhelp.com/brandingcontest/16095/Catchy-name-for-a-consumer-credit/finance-Website, accessed at 22.04.2018 (2018)

29. Squadhelp, pricing, retrieved from: https://www.squadhelp.com/squadhelp-pricing, accessed at 22.04.2018 (2018)

30. Squadhelp, tips for contest holders, retrieved from: https://www.squadhelp.com/tips-for-contest-holders, accessed at 22.04.2018 (2018)

31. Squadhelp, tips for contestants, retrieved from: https://www.squadhelp.com/tips-for-creatives, accessed at 22.04.2018 (2018)

32. Squadhelp, discussion forum, retrieved from: http://discussion.squadhelp.com/, accessed at 22.04.2018 (2018)

33. Squadhelp, blog, retrieved from: https://www.squadhelp.com/blog/, accessed at 22.04.2018 (2018) 